\title{
PARA UN ANÁLISIS REGIONAL DE LA GUERRA CIVIL EN CASTILLA Y LEÓN
}

\author{
JOSEFINA CUESTA \\ Profesora Titular de Historia Contemporánea \\ Universidad de Salamanca
}

Una atenta mirada a la abundante bibliografía sobre la Guerra Civil Española pone de manifiesto el predominio de estudios referidos a la España republicana y la menor atención prestada por la historiografía a la zona adicta a la sublevación. Esta observación, ya conocida, fue recordada de nuevo con motivo del congreso celebrado en Salamanca sobre «Historia y memoria de la guerra civil española” (1).

Son múltiples las razones que explican esta menor producción historiográfica. La larga pervivencia del régimen surgido de la sublevación y las limitadas libertades de información y expresión prolongaron la sombra sobre su origen $y$ sobre las regiones en las que se produjo.

Aćaso la España franquista es menos conocida por más largamente vivida. Nos explicamos. No está ausente de esta menor atención la oposición que P. NORA establece entre memoria e historia. La aceleración de la historia parece imponer «el fin de una adecuación: la de la memoria y la historia (...), que traduce la subversión interior de una historia-memoria por una historiacrítica» (2). No podemos olvidar que la abundancia de memorias contrasta con la menor intensidad de estudios que se proyectan sobre la España «nacional» de 1936 a 1939.

Esta sustitución de la memoria por la historia parece manifestarse en el interés creciente y el resurgir de los estudios sobre el franquismo, precisamente cuando el régimen desaparece (3).

(1) Historia y memoria de la guerra civil. Encuentro en Castilla y León. Salamanca 24-27 sept. 1986, organizado por SEGUEF, Junta de Castilla y León. Más recientemente L. G. CALLEJA y J. ARÓSTEGUI sintetizan «En Castilla y León empiezan a aparecer los trabajos, sobre todo, referentes a los primeros tiempos del régimen de Franco en la postguerra y la resistencia clandestina (...) La actividad universitaria empieza ya a entrar en el tema de la región, habiendo hoy en curso trabajos en toda ella...» «Comentario bibliográfico» en Arbor n. ${ }^{\circ} 491-492$, nov.-dic. 1986, n. ${ }^{\circ}$ monográfico dedicado a La guerra civil española, p. 242.

(2) P. NORA (dir.): Les lieux de mémoire. I. La République. París. Gallimard. 1984, pp. XIX y sigtes. Puede ser aplicable a la historiografía española sobre la República y la guerra civil, y la posterior sobre el franquismo, esa condición de discontinuidad, de ruptura, que NORA introduce en las relaciones entre memoria e historia, pá. XXXI.

(3) Remitimos a A. VIÑAS: «La historia de la contemporaneidad española y el acceso a los archivos del franquismo» Sistema n. ${ }^{\circ} 78$, mayo 1987, pp. 17-36. 
Tampoco es ajena a esta más escasa inquietud historiográfica la debilidad de la historia regional en Castilla y León, cuyo silencio se extiende no sólo a ésta sino también a otras épocas. Aunque no por ello podemos olvidar el interés del estudio de la guerra civil en la región castellano-leonesa, una de las bases del nuevo régimen. La importancia histórica de la pervivencia del modelo dictatorial que se impone, de los grupos sociales que le apoyan, de las relaciones exteriores que establece y su imposición, sobre todo, como molde político que se extiende a toda la geografía y sociedad española hacen más necesario su estudio.

Además, contra lo que se afirma en algunos sectores y a pesar de la abrumadora producción historiográfica sobre la guerra civil española, no todo está dicho sin embargo. Permanecen en el silencio - o en el olvido-temas y lagunas que reclaman una investigación; y sobre todo problemática de más difícil acometida - bien por la costosa accesibilidad a las fuentes o por la necesidad de un bagaje metodológico o de más complejo planteamiento teórico- La vida en retaguardia teje la silenciosa infraestructura de un nuevo sistema de relaciones socio-políticas que apenas se deja asir. Temas como el poder, la violencia, las redes de apoyo al ejército sublevado, la resistencia larvada y la vida en retaguardia son campos que no sólo tienen un alcance regional ni se reducen a la coyuntura de guerra y podrán arrojar luz para una más profunda comprensión de la historia más reciente, y no sólo de España.

Pero situarnos en la historia reciente no sólo significa desempolvar campos o temas menos conocidos, acaso más polémicos, significa sobre todo emplear una metodología adecuada.

Es de singular utilidad en este caso el recurso, además de la historia regional, a la historia del tiempo reciente, al estudio de las relaciones entre memoria e historia -como hemos apuntado-; a una metodología apropiada para los análisis sociales aplicable atas bases sociales que apoyan la sublevación y là de historia de las mentalidades para explicar los mecanismos mentales e ideológicos que propician y justifican este apoyo. Sin olvidar el recurso a las fuentes orales y a otros métodos de análisis de la memoria colectiva, de los que también conocemos sus límites. Habrá de tenerse en cuenta, además lo poco accesibles medios con que se cuenta para el análisis de la violencia, del poder y de la resistencia y represión.

Por todo lo anteriormente apuntado no emprendemos, pues, aquí la exposición de un trabajo acabado, sino el avance de una investigación ya en marcha de la que algunos resultados empiezan a ver la luz (4). Y se trata, sobre todo, de un intento de integración de archicos - fuentes y temas-con 
una problemática y metodología que, desde una delimitación claramente regional, desbordan los límites de la región acotada para el estudio.

\section{DE LA VIOLENCIA AL ENFRENTAMIENTO ARMADO}

De entre los temas apuntados acaso uno de los más descuidados por la historiografía sea el análisis de la violencia. La escasez de estudios marco y la dificultad del tema ya han sido puestos de relieve (5). Ello no excusa al historiador de enfrentarse a uno de los posibles «caminos hacia la guerra». El progresivo enfrentamiento social e ideológico que se produce en la sociedad castellano-leonesa en los años treinta - no es totalmente ajena a la Europa de su tiempo- se traduce paulatinnamente en una espiral de violencia especialmente patente durante 1936, sin la que es difícil comprender el progresivo enfrentamiento social que se transforma en conflicto armado. A la configuración de las posturas en la región contribuyen además de problemas de larga duración y de la consolidación de estructuras sociales, económicas y políticas, la conflictiva coyuntura de la época, en la que podemos detectar el desarrollo de la espiral de violencia gracias al análisis de diversos tipos de fuentes.

La habitual consulta de la prensa da fe de polémicas y confrontaciones, incluso de las querellas que enturbian durante este año las fiestas (6). No están ausentes complejos factores económicos, sociales e ideológicos que empujan a la conflictividad de las relaciones y a la progresiva definición política de los ciudadanos, tema que puede ser completado con el recurso a las fuentes orales. Éstas ponen de manifiesto, en ocasiones, el incremento de la tensión y del conflicto y el progresivo enfrentamiento que se produce hasta en los

(4) Estas líneas tienen sólo el carácter de anticipo de un más vasto proyecto de investigación iniciado en la Universidad de Salamanca bajo el título «Antecedentes y repercusiones de la guerra civil (1936-1939) en Castilla y León». Actualmente se encuentra en fase de realización por un equipo integrado por M. ${ }^{a}$ D. de la Calle, F. Corrionero, M. C. Escudero, A. Fuentes Labrador, J. I. Madalena, M. L. de Prado, M. ${ }^{a}$ A. Sampedro, y M. ${ }^{a}$ J. Velasco coordinados por J. Cuesta. Algunos avances fueron presentados al Encuentro sobre Historia y memoria de la guerra civil española mencionado en nota 1, y cuyas Actas verán próxima publicación a cargo de la Junta de Castilla y León. (Organismo que también subvenciona el proyecto de investigación al que nos referimos).

(5) J. ARÓSTEGUI: «Conflicto social e ideología de la Violencia, 1917-1936» en España, 1898-1936: Estructuras y cambio. Madrid. Univ. Complutense, 1984, pp. 310-343.

(6) También las fiestas, como han puesto de relieve historiadores como M. OZOUF, R. SANSÓN OS. JULIÁ, se tiñen de un marcado cariz político. Destaca el enfrentamiento que se produce en el $1 .^{\circ}$ de mayo de 1936, por ejemplo en Salamanca o en Bocigas -como pone de manifiesto Soledad Arribas en artículo citado en nota siguiente - también las ferias y fiestas patronales locales y comarcales son ocasión de encuentros y enfrentamientos colectivos. 
más pequeños núcleos rurales y que contribuyen a explicar la militancia y violencia que posteriormente se canalizará en el alistamiento en las filas del ejército.

Conflicto y violencia tales que en ocasiones superan el propio marco geográfico y social y llegan a instancias judiciales. La Audiencia de Valladolid y algunas causas, escasas, del Tribunal Supremo atestiguan bien este problema y ofrecen documentación hasta ahora inexplotada, para el análisis de esta materia. Remitimos a la presentación que de ambas colecciones documentales realizan Soledad Arribas (7) y Jesús Gaite (8), respectivamente en las Jornadas celebradas sobre "Justicia en guerra». Soledad Arribas informaba refiriéndose a la documentación de la sección Penal de la Audiencia de Valladolid: «durante el año 1936, tanto antes de empezar la guerra, sobre todo a partir de febrero de 1936 (...), como durante los primeros meses de ella, hay muchos delitos por enfrentamientos de personas de distinta ideología con el resultado de lesiones y muertes» (9). Documentación judicial que además de posibilitar una aproximación cuantitativa, puede desvelar algunos motivos del conflicto junto a la no desdeñable aportación del lenguaje.

De esta forma los individuos van tomando posición respecto a los grupos sociales y políticos en pugna, y van consolidando credos heredados y nuevos en posturas «pro y contra» la situación creada por la República respecto a sus problemas fundamentales.

La espiral de violencia y el acontecer histórico que se desliza desde la primavera del 36 actúan como catalizadores que potencian actitudes profundamente arraigadas en la región (10) y contribuyen a la definición de intere-

(7) «Fondos documentales de la justicia ordinaria en la España «nacional» (a través de los conservados en la Audiencia territorial de Valladolid)» ponencia presentada en las «Jornadas sobre administración de justicia durante la guerra civil española: Instituciones y fuentes documentales». Organizadas por el Archivo Histórico Nacional, Sección Guerra Civil. Salamanca 2628 noviembre 1987, (ejemplar reprografiado).

(8) «Fondos documentales para el estudio de la guerra civil española, custodiados en el Archivo Histórico Nacional de Madrid», ponencia presentada en las mismas Jornadas de nota anterior (ejemplar reprografiado). Entre la documentación de Tribunal Supremo y referida a los años treinta las causas que provienen de la región castellano-leonesa se refieren fundamentalmente a tenencia ilícita de arinas, delitos de imprenta, atentado a la autoridad y revisiones del ejercicio de la autoridad por parte de algunos gobernadosres civiles. (el de Burgos, por ejemplo). A. H. N. Fondos contemporáneos. Tribunal Supremo, Legs. 128, 135, 142, 143, 145.

(9) S. ARRIBAS, op. cit. p. 3.

(10) Son múltiples los ejemplos que se podrian aducir respecto al progresivo fortalecimiento de posturas tradicionales, apoyadas en el sector agrario, citamos, a modo de muestra el acuerdo entre la Federación Católica Agraria Salmantina y el Bloque agrario firmado por Lamamie de Clairac y Ernesto Castaño en Salamanca, el 3 de agosto de 1935. Archivo Caja Rural. Salamanca. 
ses y objetivos de los que, no tardando mucho, serán las bases sociales que apoyan al ejército sublevado.

\section{APOYOS SOCIALES Y ECONÓMICOS A LA SUBLEVACIÓN}

Es conocido que una de las notas definitorias de la región castellanoleonesa sea su predominante actitud de apoyo respecto a la sublevación militar; aunque no sin excepciones, y a ello nos referiremos en un intento de aproximación al silenciado tema de resistencia, oposición y represión.

Los apoyos sociales en esta región fundamentalmente agraria han sido ya puestos de manifiesto por diversos autores y analizados como un doble y mutuo apoyo por J. Aróstegui en La guerra civil española, cincuenta años después fundamentalmente (11).

Ahí están los apoyos campesinos, que se anclan en una mentalidad conservadora, rural, vinculada a la propiedad -aún en aquellos «propietarios muy pobres» definidos por J. J. Catillo- (12) y estimulada por la confesionalidad católica, fomentada en los sindicatos agrarios católicos y potenciadas en los partidos agrarios; simpatizantes también con las palabras de orden, familia, religión y con ciertos valores tradicionales de los que en adelante se apropiará el régimen presidido por los militares.

Apoyo agrario que no sólo proporciona bases sociales, sino organizaciones y medios de expresión y sobre todo avituallamiento. No es indiferente para el ejército sublevado que en el verano de 1936 las cosechas de trigo se conserven todavía en muchos almacenes castellanos. La legislación del régimen militar está salpicada de medidas respecto al sector agrario. Interesan las subsistencias, especialmente las existencias de trigo y harina, las cosechas de vinos, también los créditos concediendo facilidades económicas para la sementera -créditos que tienen un claro destinatario social, el propietario-, entre otra mucha normativa. Legislación que es exponente de una reciprocidad de apoyos, so sólo de las bases agrarias al régimen militar, sino de éste a los propietarios al menos durante la guerra civil. Ha quedado suficientemente apuntado el significado para estas relaciones de la temprana creación del Servicio Nacional del Trigo (13).

(11) J. ARÓSTEGUI: «Los componentes sociales y politicos» en M. TUÑON DE LARA y otros: La guerra civil española, 50 años después, Barcelona, Labor, 1987, pp. 45 ss.

(12) Propietarios muy pobres. Sobre la subordinación política del pequeño campesino. Madrid, Servicio de publicaciones agrarias, 1979.

(13) Ver, además de los estudios más generales sobre la guerra civil, C. BARCIELA LO. PEZ: La financiación del Servicio Nacional del Trigo, 1937-1971. Madrid. Banco de España, Servicio de Estudios, 1981. 
Apoyo que reviste múltiples fórmulas y que no sólo se concreta en el sector agrario. Un papel similar al jugado por las Federaciones católico-agrarias representan otras organizaciones de carácter católico, como el círculo católico de obreros de Burgos y su Caja de Ahorros.

No es desdeñable tampoco la aportación de personal al nuevo régimen que realizan gran número de grupos de profesiones.

Las «élites» originarias del régimen naciente se reclutan, en gran medida, entre funcionarios de las ciudades castellanas que de este modo transforman a las élites provinciales en personal de las comisiones gestoras y miembros dirigentes del nuevo régimen. Un exponente de ello es, por ejemplo, la constitución de la Comisión «para la reorganización de los servicios de justicia», nombrada por la Junta de Defensa, integrada totalmente por funcionarios de Justicia de Burgos (14).

Bases sociales, avituallamiento, «élites» políticas que se orquestan con unas bien dirigidas masas de apoyo, que expresan su fervor ante el nuevo régimen siguiendo el molde de los movimientos de masas de los años treinta, sin escatimar concentraciones en las "capitales» del régimen con motivo de diversos acontecimientos, - del Te Deum a la presentación de credenciales de los repreșentantes alemán e italiano- a la vez que son receptores y emisores de "gritos" y "símbolos" bajo los que se difunde la nueva ideología.

Pero no sólo la población, también el espacio toma partido con ella.

La región castellano-leonesa, incorporada a la sublevación desde los primeros dias, se constituye en base de operaciones para la expansión y la dirección de la guerra. Mientras Salamanca y Burgos se reparten la «capitalidad» del régimen que nace, los órganos de Estado se derraman por las distintas ciudades. Desde ellas se dirige la guerra hacia los frentes de Madrid o del Norte y se realizan contactos con otras capitales europeas. El espacio de retaguardia aunque no vive el frente tambień se militariza y la geografía de guerra se extiende a todos los rincones, aunque se dejará sentir en escalas muy diversas. No obstante se extiende también a los más diveros objetos.

(14) Comisión nombrada el 27 de agosto de 1936 e integrada por Alejandro Gallo Artacho, magistrado de la Audiencia Territorial de Burgos; don Luciano Álvarez Valdés, fiscal de la misma; Valeriano P. Flórez-Estrada, jefe de la Abogacía del Estado en la Delegación de Hacienda de Burgos; Antonio de Vicente Tutor, juez de 1. ${ }^{a}$ instancia e instructor de la misma ciudad. La Comisión de Justicia de la Junta Técnica del Estado ha dado cabida dos meses más tarde a una composición ya regional, está formada por personas de carrera jurídica procedentes de Burgos, Valladolid, Soria, Cuéllar, Mondragón y Las Palmas. Archivo de Presidencia del Gobierno. Junta Técnica del Estado. Leg. $1, \mathrm{n} .{ }^{\circ} \mathrm{5c}$. Para más información sobre esta comisión ver I. BERDUGO, J. CUESTA, M. ${ }^{a}$ D. de la CALLE y M. DANERO: «EI ministerio de Justicia en la España "nacional», ponencia presentada a las Jornadas sobre Administración de Justicia, cits. en nota 7. 
La requisa en el mecanismo de militarización y beligerancia de hasta los objetos más nimios. Requisa que se dirige a tres importantes sectores, hemos apuntado la rural y agraria, un elemento de la guerra tradicional, que se completa con la requisa de edificios para usos militares y, en muchos casos, para la utilización por organismos del Estado naciente. Pero un tercer elemento se añade a estas requisas tradicionales, algunos aparatos procedentes de la segunda revolución industrial serán objeto de especial interés e instrumentos de la mínima infraestructura de un poder que emerge: la radio, el coche, la máquina de escribir e incluso los rayos $X$ - para usos sanitarios - son objeto de inmediata requisa.

Pero con el concepto de requisa hemos franqueado un umbral en el tema planteado de apoyo a la sublevación.

Un apoyo difícil de seccionar de la imposición. Necesitariamos ser cautos con las fuentes para distinguir diversos niveles de adscripción al régimen militar en sus orígines: apoyo, asentimiento, sumisión, reticencia y resistencia. La actitud ante las requisas permiten deducir estas diferencias y marcar distancias entre la propaganda y los hechos.

Las requisas hacen aflorar una compleja problemática que origina la guerra en retaguardia. Muestran una guerra no en los frentes sino intestina, imbuída en la propia vida cotidiana. Mediante ella se impone una militarización de la vida civil, de la propiedad, del domicilio, de los utensilios. Aunque no ocultan tampoco una atomización de la autoridad y el poder. Las quejas sobre quién ordena las requisas, y quién las hace, ponen de manifiesto la desarticulación entre los distintos niveles de la autoridad y entre los diversos campos de acción de ésta (15), conflictos que serán solucionados por la vía de la jerarquización militar. No oculta, además ciertos conflictos entre organis-

(15) Abundan las quejas elevadas a la autoridad militar sobre requisas espontáneas o autónomas realizadas por la Legión Cóndor o por la Falange en Salamanca. A veces, además sobre un mismo local recaen sucesivas requisas desorganizadas. Por ejemplo una vivienda de la plaza de Colón, $n .{ }^{\circ} 1$ (Salamanca) requisada sucesivamente por la Delegación Especial de policía, que será ocupada por la Delegación de Orden Público, de lo que el Gobernador militar no tiene conocimiento. La queja del propietario es un buen exponente de esa cierta resistencia a que hemos aludido, dirigida al Gobernador Militar en estos términos «Distinguido Sr. mío: En el mes de febrero de 1937 me fue requisada la casa que habitaba en la plaza de Colón, $n .{ }^{\circ} 1$, con destino a la Delegación ESPECIAL de Policía. Habiendo desaparecido aquel servicio, era natural que se me hubiera devuelto y sobre este particular tengo entablada la correspondiente reclamación. Dicha casa está hoy ocupada por la Delegación de O. P. (que le impone desocuparla para realizar obras) (...) causándome con esta determinación un gran perjuicio que entiendo no es justo.

Claro que si forzosamente se me obliga a ello habré de resignarme; pero no quiero dejar de expresar ante la superior Autoridad de V. E. este hecho, para que examinándole con la sere- 
mos civiles y militares (16) e incluso entre el poder militar y algunos organismos extranjeros, la Legión Cóndor por ejemplo parece desconocer a las autoridades militares españolas en el ámbito salmantino.

Pero estos datos son sólo exponente de un problema de fondo ya apuntado, un proceso de articulación del poder que se produce paulatinamente (17) y que acabada la guerra todavía presenciará algún conflicto. Ayuntamiento y Diputación salmantinas se esfuerzan por desembarazarse de la intervención militar en determinados servicios civiles. Pero ésta es la otra cara de la moneda, pues la requisa proporciona, sobre todo, instrumentos de apoyo social y también económico. Apoyo social que no es posible sin concretarse en soporte económico (18) y que los sublevados aprovecharán también como propaganda.

Hemos apuntado el apoyo rural y de bases campesinas, que es recogido, en ocasiones, por cajas rurales; otras cajas de ahorro de la región también prestarán su concurso económico, de grado unas veces, sobre todo en los primeros meses de la sublevación, impuesto otras, con reticencias veladas - en otros casos, lo mismo que sucede entre los particulares.

nidad y buen juicio que le distingue, si entiende que es justa mi pretensión, disponga la suspensión de las órdenes verbales que se me han dado y queden las cosas.... El Gobernador Militar cursará la protesta al Delegado de Orden Público cuatro días después, arguyendo "como quiera que este Gobierno no ha tenido intervención en la requisa...» Archivo Gobierno Militar, de Salamanca. Legajo Asuntos Varios.

(16) En el mismo legajo y archivo se conserva una nutrida documentación sobre la reclamación que el Ayuntamiento salmantino hace a las autoridades militares, en 1939, de una tanqueta contra incendios "Geo» que éstos conservan y que aquél estima de su propiedad. Similares litigios existen entre Diputación y diversas instancias militares a las que aquélla reclama la devolución de los gastos efectuados para acondicionar la Residencia provincial de niños para fines militares.

(17) Son múltiples los mecanismos para la organización del poder en todos los campos. Referente al tema de las requisas la repetición de bandos manifiesta la dificultad de lograrlo.

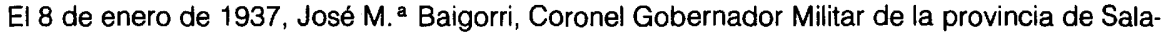
manca y Delegado del General del Ejército del Norte «hace saber (...) [que/ cualquier requisa efectuada por autoridades o por organizaciones que no sean las enumeradas en este Bando o por particulares será sancionada con toda energía, siendo inmediatamente detenido su autor y entregado al Jefe Militar más próximo. Los propietarios víctimas de requisa no autorizada por este Bando, quedan obligados a denunciarme el hecho por el conducto más rápido». El 1. ${ }^{\circ}$ de julio del mismo año el General Jefe del Ejército del Centro, Andrés Saliquet restringe la capaciơlad de requisa al General Jefe del Ejército del Centro, Generales de Cuerpos del Ejército y Generales Jefes de divisiones restándosela al Gobernador militar, que la tenía en el bando de principios de año. Aunque mantiene exactos los puntos $3 .^{\circ}$ y $4 .^{\circ}$ copia idéntica del Bando de enero y que hemos transcrito más arriba.

(18) Mencionamos aquí este apoyo económico fundamentalmente como expresión del apoyo social y propaganda y limitado a aquellas instituciones de las que la historia guarda memoria, pues, además de la dificultad de rastrear su importancia cuantitativa, es un tema que habia de ser abordado por un historiador económico. 
Este soporte económico como expresión del social y vehículo de propaganda ofrece una manifestación masiva en las suscripciones populares: subsidio pro combatiente, auxilio de invierno, plato único, día sin postre, deducciones del sueldo de funcionarios, etc. Ayudas institucionalizadas unas y elemento de coacción muchas, que de nuevo nos sitúan en el umbral entre apoyo-imposición, aspecto este último que será factor de contrapropaganda hacia las fuerzas sublevadas, en la opinión republicana.

La compleja relación entre apoyo e imposición no se ejerce sin unos mecanismos de poder que actúan desde los primeros días de la sublevación. Se ha aludido a la laguna historiográfica existente sobre este tema, y la problemática que plantea en las dos zonas en guerra. Algo se ha escrito sobre el poder en la España republicana. También se ha aludido a la importancia que en la España sublevada tienen las fórmulas militares como instrumento de integración del poder, aunque tampoco se olvida la difícil unificación de los distintos grupos políticos. Pero no acaba ahí el problema.

El binomio apoyo social e imposición nos introduce en el entramado del poder y su progresiva articulación y expansión, en los mecanismos empleados y el modelo que se establece para el paso del apoyo atomizado a la organización del espacio.

Es posible conocer el papel que las élites provinciales y locales - bases sociales y grupos políticos- juegan en la estructuración del poder estatal, provincial y local. Tarea menos fácil es la organización de las diversas instancias de la administración del Estado para un dominio del espacio; la articulación progresiva de la administración de justicia puede ser un claro ejemplo de los problemas y dificultades que presenta la estructuración de un nuevo estado en una coyuntura de guerra, aunque éste se ancle en realidades ya existentes: funcionarios, estructura y organización administrativas, etc.

Incluso el dominio del espacio plantea serios problemas de poder, como sucede en las requisas, donde no se respetan ni la jerarquía militar ni la distribución de competencias, relativamente confusas durante bastantes meses. La intervención personal y directa del "caudillo» dirimirá cuando estos conflictos se produzcan y una normativa minuciosa intentará zanjar los roces que se producen en los distintos campos entre el espacio y el poder.

Pero el espacio es sometido por otros medios más difusos.

Los lugares de memoria (19) monumentos, calles, ritos, mitos y símbolos (20) ofrecen materia abundante para la configuración y exposición de la «liturgia» del régimen. Las calles - nuevamente nominadas, como en cada cambio de régimen político- dan fe de la memoria histórica que se pretende implantar y del dominio nominador del espacio, pero a la vez sirven de marco, 
sobre todo en «las capitales» del régimen, para la animación, la aclamación y la elocuencia; no podemos despreciar la importancia que en las movilizaciones de masas propias de la época - tan cultivadas por los regimenes fascistas - tienen las manifestaciones, desfiles, dircursos, etc., aspecto al que aludiremos más adelante al referirnos a la vida cotidiana. Golpe militar, apoyo social y económico, dominio del espacio, articulación del poder y reconocimiento internacional, más un complejo entramado ideológico contribuyen a la formación del «Estado». Tema que ha sido objeto de atención historiográfica, aunque no agotado, y que rebasa los límites de un análisis regional. Pero sin duda los temas apuntados más arriba contribuyen a perfilar la contribución regional, que no fue escasa, a su construcción.

\section{IDEOLOGÍA, CULTURA Y VIDA COTIDIANA}

Aunque también desborda el marco regional, representa una importante contribución al nuevo régimen la difusa mentalidad sustentada por los grupos que le apoyan. Mentalidad que completada con aportaciones provenientes de las nuevas corrientes existentes en la Europa de los años treinta y organizadas por el poder en su propia exaltación se transforman en un vehículo ideológico de primera línea.

La vida cotidiana de la retaguardia está ritmada progresivamente por esta nueva concepción política y social, que se ancla en la mentalidad, valores y simbolos ya existentes y que propicia una vuelta a los hábitos familiares y

(19) Sobre el análisis de los lugares de memoria remitimos a la extensa e innovadora obra de P. NORA, mencionada en nota 2 que se completa con les lieux de mémoire. II La Nation. París, Gallimard, 1986, 3 vols. Puede verse un intento de aplicación de este tipo de estudios a la historia española en J. I. MADALENA y otros: «Los lugares de memoria de la guerra civil en un centro de poder. Salamanca 1936-1939", trabajo de investigación presentado en el Congreso sobre «Historia y memoria de la guerra civil», ya mencionado.

(20) Los símbolos ocupan un lugar elocuente entre los lugares de memoria sobre todo en la producción del discurso ideológico de un régimen y adquieren singular relieve en los años treinta. A ellos alude alguna de las historias de la guerra civil española. Pero su estudio podría ser profundizado siguiendo los métodos empleados por M. DOMMANCET o M. AGUILHON, por ejemplo para Francia. Ver también Louis BARÓN: La symbolique militaire en France. Bibliographie. Service historique de l'Armée, 1969, multicopiado. A título de ejemplo recordemos el Víctor que el nuevo régimen tomará prestado de la tradición universitaria salmantina o el Yugo al que se encargarán de cargar de significado algunos ideólogos del momento: «desde que vino la República hemos gemido bajo una tiranía y un yugo que no era precisamente el de lsabel la Católica que ahora ostenta la Falange Tradicionalista de las J.O.N.S., sino un yugo intolerable e inaudito..." Remigio VILARINO, S. J.: "Aclamaciones libres». Hechos y dichos, T. II. n. ${ }^{\circ} 41$, dic. 1938, pp. 129-137, (la cita es de la p. 131 y el subrayado es nuestro). 
a los comportamientos religiosos tradicionales como pueden atestiguar algunas fuentes de archivos diocesanos (21).

Al servicio del régimen se aplican también las instituciones existentes. Un estudio detallado merecen las dos Universidades de la región, que contribuirían de modo especial a la constitución del nuevo régimen. Son cantera de políticos y fuentes de estructura jurídica, ahí están las listas de catedráticos de Derecho solicitados por el Gobierno recién creado en 1938 para proveerse de expertos. Es fuente de poder, de producción ideológica y de órganos de control (22), el Rector está dotado de poderes en la depuración de funcionarios de educación, y no sólo universitarios. A la vez que ofrece infraestructura necesaria para la construcción teórica y de los órganos del Estado. El Tribunal Supremo, constituido provisionalmente en Vitoria en 1938, optará por establecerse en Salamanca o Valladolid como sede permanente, ciudades universitarias en lo que cuenta con legislación y documentación imprescindible para su trabajo (23).

Si las universidades contribuyen a la producción y estructura del régimen,

(21) La información eclesiástica sobre el cumplimiento pascual, que los párrocos debian enviar periódicamente al obispado aporta otros datos de gran interés para conocer las costumbres de la población castellana y sobre todo sobre la permanencia o cambio de sus hábitos en los años treinta. Matrimonio y enterramiento civiles, asi como lecturas de prensa católica o no católica son algunos índices que pueden testificar esos posibles cambios de comportamiento, $y$, en el fondo, la emergencia de otra mentalidad.

(22) Más allá de ciertos datos anecdóticos o biográficos conocidos las Universidades de Valladolid y Salamanca no son ajenas a la configuración del régimen. Además de su función de orientación y represión sus aportaciones superan los campos puramente culturales o ideológicos como en el Informe de la Universidad de Valladolid sobre la situación de las provincias vascongadas bajo el dominio rojo-separatista. Valladolid. Tall. tip. Cuesta, 1938, 253 pp.

(23) La constitución del Tribunal Supremo del Gobierno de Franco ofrece abundante información sobre esta materia. Su tarea, después de reclutar el personal jurídico imprescindible, se dirige a la búsqueda de un lugar adecuado para su instalación. Entresacamos algunos de sus acuerdos, que han de ser objeto de más detenido estudio: Constituido - en los documentos se borrará la palabra constitución para sustituirla por la de organización- el Tribunal Supremo el 14 de octubre de 1938, el 9 de noviembre eleva un oficio al Subsecretario de Justicia informándole que «entre las múltiples dificultades que van surgiendo al iniciar la organización del Tribunal que me honro en presidir, una de las más destacadas y que requieren urgente resolución es la falta de una biblioteca jurídica de indispensable y diaria utilización» y solicitan que la Comisión Central administradora de bienes incautados por el Estado les entregue en depósito libros de carácter jurídico que les sean de alguna utilidad. Constituida la Sala de Gobierno del Tribunal Supremo el 26 de noviembre de 1938 y a instancias del Gobierno de que «evacúe un informe acerca de la capital que pudiera reunir las condiciones más adecuadas para la instalación del Tribunal Supremo» acuerda «iniciar las gestiones preparatorias en Valladolid, Salamanca y Pamplona». Gestiones que llenan las actas del mes de diciembre y ofrecen una notable información sobre la actividad política y viḍa cotidiana recibida en Pamplona «desde luego no mostraron el calor y estusiasmo que se esperaba por la instalación del Tribunal Supremo en dicha capital, mostrándose parcos en hacer ofrecimientos...". Archivo del Tribunal Supremo. Legajos 6854-7 y 7715-31. 
la prensa y propaganda ofrecen uno de los mejores medios de circulación y distribución de su ideología, de sus consignas, y de movilización de la población.

Conocemos el papel protagonista de la radio durante estos años y hemos de reconocer que son más abundantes los estudios sobre esta materia procedentes de disciplinas afines a los medios de comunicación que del campo historiográfico. No obstante no puede desvincularse el nombre de Salamanca y el entorno del Cuartel General de Franco de la creación de Radio Nacional de España.

La prensa periódica mantiene sin embargo el protagonismo adquirido a principios de siglo. Los años de guerra ven multiplicarse de forma asombrosa los periódicos sobre todo en algunas capitales castellano-leonesas, Burgos, Salamanca y Valladolid ven la publicación de medio centenar de órganos de prensa en esos años. Los elencos bibliográficos y la Hemeroteca municipal de Madrid dan buena fe de ello. Pero la consulta de estas fuentes, impone junto a la metodología específica, las cautelas añadidas por su fuerte ideologización, por su función de propaganda y por los mecanismos de la censura.

La «liturgia» a la que nos hemos referido anteriormente no es uno de los menores instrumentos de propaganda.

Pero sin duda, la época ofrece una especial cantera propagandística en las memorias y publicaciones originadas con motivo de la guerra.

Si el Archivo Histórico Nacional, Sección Guerra Civil de Salamanca ofrece un filón inexplotado de publicística y propaganda de la España republicana, la Biblioteca del Archivo Municipal de Burgos cuenta con un notable fondo de publicaciones generadas por la guerra en la zona nacional. No podemos extendernos aquí en hacer su presentación. Sólo recordamos el interés que este fondo reviste, ya apuntado por J. Aróstegui en la revista Arbor (24), y la ocasión que ofrece para el estudio de una biblioteca como lugar de memoria histórica (25), y para el análisis de la relación entre memoria, memorias

(24) E. G. CALLEJA y J. ARÓSTEGUI, op. cit. en nota 1, p. 242.

(25) La Biblioteca del Archivo Municipal de Burgos conserva entre sus mil cuatrocientos libros, un millar dedicado a la Guerra Civil y publicados en la época y escritos todos ellos desde la perspectiva de la España «nacional». El interés de este fondo radica no tanto en la aportación histórica de los libros en sí, cuanto en la posibilidad que ofrece del estudio paralelo de la construcción de un fondo y de la elaboración de una determinada memoria colectiva, a la vez que el proceso de construcción de una historia. De esta manera cada volumen puede ser analizado como elemento de una biblioteca y como fruto y factor de una historia; cada obra será reflejo de la conquista de un territorio, recuerdo de una hazaña bélica que al quedar escrita y ser leída actúa como estímulo en pro de esa misma guerra y del régimen que la impulsa; será justifica- 
e historia y para la disección de su contenido en el marco de prensa y propaganda al que ahora nos referimos.

Un aspecto silenciado de vida cotidiana en retaguardia durante la guerra civil es el referente a la acción social. Algún interés mayor y aunque aún escaso ha suscitado la historia de la Sanidad en el período bélico.

La acción social en la España sublevada tiene el interés historiográfico de ofrecer una doble quiebra: temporal y espacial. El modelo que establecerá el nuevo régimen, aún sin romper institucionalmente con la tradición española, -el Instituto Nacional de Previsión será heredero del antiguo Instituto de Previsión y se prolonga sin solución de continuidad desde 1909 hasta 1976, aunque duplicado durante la guerra y con actividad autónoma en ambas zonas, en la franquista se reconstruye a partir de algunos de sus dirigentes evadidos de Madrid - supone una ruptura con el modelo de política social establecido por la II República y que responde adecuadamente a l 's moldes europeos; mientras que el programa que establece el nuevo Estado parece recuperar un viejo modelo asistencial, a pesar de la distorsión del lenguaje oficial (26).

Podemos hablar en efecto de dos modelos similares y diferentes de acción social, en España, uno en cada zona. La legislación laboral será claro exponente de esta diversidad.

\section{RESISTENCIA Y OPOSICIÓN}

Si la sublevación y el nuevo régimen tropiezan con dificultades para articular su propio poder, tampoco desconocen los originados por la incapacidad. Hemos aludido a reticencia y resistencia. Pasados los primeros días del golpe y la represión de la primera hora, la oposición abierta se formula en la huida y la guerrilla - los guerrilleros refugiados en la montaña zamorana y leonesa han sido ya objeto de alguna atención (27) -, o es objeto de la re-

ción de la lucha o búsqueda de aliados en ella y ofrece, además, tanteos y proyectos para implantar las bases del régimen, o panégirico de la nueva situación. Su estudio, que se ofrece laborioso, cuenta ya con precedentes en algunas bibliotecas francesas: M. CARBONIER: «Une bibliothéque populaire en XIXe, la bibliotheque populaire protestante de Lyón». Memoria para la obtención del título de bibliotecario, Lyón 1976, cit. por P. MARIE: «La Bibliothéque des Arnis de l'Instruction du Ille arronchissement en P. NORA, op. cit. en nota 2, pp. 323-351.

(26) Preocupaciones, programas, destinatarios, instituciones y presupuestos contribuyen a definir el modelo de acción social elegido. No cabe olvidar tampoco la adecuación o no de la legislación del nuevo régimen a las directrices internacionales, de gran arraigo ya en la época y a las que la II República había mostrado su adhesión. Ver. M. SAMANIEGO: Los seguros sociales en España. III Hacia la unidad de los seguros sociales. Madrid. Ministerio de Trabajo, (en prensa).

(27) Además de las obras de HEINE sobre la querella en Galicia ver S. SERRANO «La gue- 
presión organizada -cárcel y cementerio dan fe de ella, o permenece aún en el silencio que la memoria popular se resiste a levantar- aunque la mayoría parece optar por la formulación pasiva. Una oposición silenciosa y larvada se oculta bajo algunas fórmulas de resistencia. Las deserciones de filas pueden obedecer, entre otras muchas a factores de este tipo; las requisitorias aparecidas en el Boletín oficial de la Provincia dan fe de ellas, además de la resistencia a las incautaciones de locales o domicilios o a recibir órdenes militares. También algunas mujeres se resisten a cumplir el Servicio Social y severas órdenes del Gobernador militar amenazan con el castigo a los directores de hospitales que justifiquen en falso su realización.

Junto a ellos, reciben la condena del régimen, sea cual fuere su postura respecto de él, los acaparadores de productos - un tema que tendrá gran importancia en los años cuarenta-, y los soldados que venden la ropa traída del frente o los ciudadanos que compran esta ropa sustraída al ejército. Pero éstos son sólo exponentes parciales y esporádicos de una actitud difícil de recuperar para la historia pero existente durante la guerra en esta región.

Pues la beligerancia que impone el régimen militar no acaba con la guerra. El año 39 y siguientes si bien presencian el fin de aquélla no dan paso al «retorno de la sociedad civil» que no se producirá hasta «cuarenta años después». La guerra queda arraigada en la población castellano-leonesa en múltiples aspectos. De todos ellos sólo apuntamos algunos. Salamanca y Burgos cederán su capitalidad en favor de Madrid, aunque no se verán desguarnecidos de su población militar que prolonga la ocupación de locales hasta bien entrada la década siguiente. Y ya desde principios de 1939 se preparan a la represión que se avecina. La documentación militar -sobre todo la referente a prisiones y campos de concentración- evidencian una incansable preparación de espacios para la localización de prisioneros. En Salamanca se habilitan un grupo escolar y la plaza de toros como campos de concentración en espera de 50.000 prisioneros que se anuncian para esta plaza. Preparativos que recuerdan la propaganda republicana contra Franco ante la caida de Euskadi: "carceleros, necesitan más carceleros".

De esta forma el fin del conflicto bélico nos avoca a un tema historiográfico descuidado en nuestro país y que desde hace años reclama un interés creciente entre los historiadores europeos, sobre todo en el marco historiográfico de los Institutos de historia del presente francés, alemán y austríaco, el de los movimientos de población como consecuencia del fenómeno bélico.

rrilla antifranquista en León (1936-1951) Junta de Castilla y León, 1986 y A. MARIN BARRIOS,

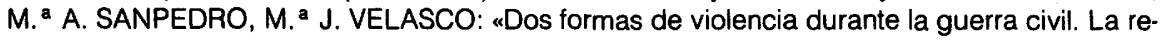
presión en Salamanca y la resistencia armada en Zamora». Trabajo de Investigación presentado al Encuentro sobre «Historia y memoria de la guerra civil», citado. 